\title{
Understanding entrepreneurial intentions: A developed integrated structural model approach
}

\author{
Kourosh Esfandiar, Mohamad Sharifi-Tehrani, Stephen Pratt, Levent Altinay
}

\begin{abstract}
The primary objective of this study is to develop the pioneering version of Krueger's (2009) integrated model of entrepreneurial intention (EI) and to empirically test the new model in explaining individuals' intentions of entrepreneurial activities. The data were collected by the self-reported in-person and electronic questionnaires from a population of tourism students from several universities in Iran. The results of partial least squares estimations indicate that desirability is the main determinant of entrepreneurial goal intention (EGI), followed by selfefficacy, feasibility, opportunity, attitude, and collective-efficacy, while social norms do not influence EGI. Also, EGI strongly influences entrepreneurial implementation intention. Concerning the modification effect, the impact of perceived opportunity on EGI tends to increase when an individual has a high propensity to act. The findings provide policy makers with important insights into how to nurture tourism students' EIs through educational programs.
\end{abstract}

Keywords: Entrepreneurial goal intention; Entrepreneurial implementation intention; Integrated model; Tourism students; Structural equation modeling. 


\section{Understanding entrepreneurial intentions: A developed integrated structural model approach}

\section{Introduction}

Entrepreneurship is an innovative and creative process where there is potential to add value to products, create job opportunities, raise productivity, revitalize and diversify markets, improve social welfare, and more broadly to develop the economy (Guerrero, Rialp, \& Urbano, 2008). The benefits of entrepreneurship apply to tourist destinations as well, in that, by means of entrepreneurial activities, various sectors of the tourism industry can respond to tourists' needs, thereby contributing to tourists' travel experiences and the destinations' economy (Ryan, Mottiar, \& Quinn, 2012). This is perceived to be particularly important for developing countries where there are more constraints on resources to enrich and diversify tourism products and experiences (Sharifi-Tehrani, Verbič, \& Chung, 2013). To ensure a continuous supply of entrepreneurs, academics and practitioners need to know how earlystage potential entrepreneurs' intentions originate as well as what factors stimulate entrepreneurship.

Given the significance of the pre-business venture formation phase, the focus of this research is to explore how a potential entrepreneur's cognitive state of intention directs him or her toward a business venture, emphasizing that the greater the intensity of intention, the higher the probability of entrepreneurial activities (Botsaris \& Vamvaka, 2016). Recent research notes the importance of intention-based models as they include a theory-based and process-oriented perspective to explain precursors of Entrepreneurial Intentions (EI). To this end, there have been a number of competing models of behavioral intentions in the literature identifying a somewhat similar set of constructs. Two of these frameworks are the Theory of Planned Behavior (TPB) (Ajzen, 1991) and Shapero's model of the Entrepreneurial Event 
(SEE) (Shapero \& Sokol, 1982). These models have been central to entrepreneurship research to date, yet there exists a relatively unexplored alternative approach to integrate the two models and introduce a new, more developed and systematic model into the entrepreneurship literature.

To shed further light on the emerging field of integrated entrepreneurial intention models, the primary objectives of this study are to develop the pioneering version of Krueger's (2009) integrated model of Entrepreneurial Intention (hereafter KEI) and to empirically test the new model in explaining individuals' intentions to undertake entrepreneurial activities and decisions. In particular, this research responds to calls by a number of studies (e.g., Schlaegel \& Koenig, 2014) for a systematic aggregation of alternative intention models in the entrepreneurship literature to improve their predictive validity. This study's target population consists of tourism students from several universities located in Tehran, the capital of Iran. As Gurel, Altinay, and Daniele (2010) argue, tourism students are a potential driving force of entrepreneurship in the industry, who are facing imminent career decisions. Given that the education offered by universities could function as a motivational factor that transforms students' aspirations and attitudes into self-employment (Wang \& Wong, 2004), investigating their business intentions gives policy makers and scholars important insights into how to nurture students' entrepreneurial thinking through customized educational programs. This could prove particularly advantageous in developing countries where, in spite of tourism growth, there is a scarcity of well-trained local workforces in different sectors of the industry (Echtner, 1995). However, while a significant body of literature is devoted to entrepreneurial intentions, there is a paucity of research to date investigating this concept in the context of tourism in general, and in the context of tourism in developing countries, in particular. 


\section{Theoretical background}

\subsection{Research model development}

Intention-based models, a theory-oriented and process-oriented approach, represent direct analysis of entrepreneurship behavior. They provide insights into how one's decisions for a new venture are made before examining practical opportunities on the part of the individual (Low \& MacMillan, 1988). Entrepreneurial intention (EI) is defined as "the conscious state of mind that precedes action and directs attention toward entrepreneurial behaviors such as starting a new business and becoming an entrepreneur" (Moriano, Gorgievski, Laguna, Stephan, \& Zarafshani, 2012, p. 165).

Intention models, along with the indirect influences of individual factors, offer a way to understand the direct precursors to business start-ups and predict consequences of intentions in that they capture longer-term tendencies held by individuals. These models offer a richer understanding than examining personal or situational factors alone (Krueger, Reilly, \& Carsrud, 2000). Intention models help understand and predict individuals' planned behaviors, such as pursuing a tourist enterprise venture, and explain how potential entrepreneurs perceive opportunities through analyzing their intentions and the factors affecting these intentions (Shepherd \& Krueger, 2002).

Of the extant intention models, Ajzen's theory of planned behavior (Ajzen, 1991) has been widely operationalized and examined in the entrepreneurship literature. The TPB was grounded on the premise that three determinants: (a) attitude toward outcomes of the behavior, (b) social/subjective norms and (c) perceived behavioral control, directly provide the motivational basis for intention to perform the behavior. Attitude toward outcomes of the behavior refers to the degree to which an individual has a favorable or unfavorable appraisal of the behavior in question. Social/subjective norms refer to the extent to which an individual 
perceives his or her behavior is consistent with significant others' thoughts. Perceived behavioral control is the extent to which the target behavior is within a decision maker's ability. This determinant largely overlaps with Bendura's perceived self-efficacy concept (Bendura, 1989), defined as one's personal beliefs regarding their abilities to succeed in performing the target behavior.

Another established intention model, but specific to the domain of entrepreneurship research, is Shapero's model of the entrepreneurial event (SEE) (Shapero \& Sokol, 1982) which was formulated nine years prior to the TPB (Ajzen, 1991). The SEE posits that the intention to initiate an entrepreneurial event such as establishing a new venture requires three critical antecedents; perceptions of desirability and feasibility of an EI (both personal and $\underline{\text { social) as well as propensity to act. Feasibility and desirability themselves are influenced }}$ directly by self-efficacy and personal desirability, respectively. While desirability and feasibility are conceptually, to some extent, homologous to attitude and perceived behavioral control in the TPB respectively, adding propensity to act to the SEE contributes to the entrepreneurial process by capturing the potential for identification and recognition of a credible new venture opportunity. Acting upon credible entrepreneurial opportunities is vital given that favorable attitudes and social norms toward an EI are not sufficient to become intent to activate an entrepreneurial event. In their investigation among higher education students, Krueger et al. (2000) compare these two models' predictive power using regression analysis and demonstrate that both models are robust but, as expected, TPB's exogenous variables do not explain entrepreneurial intention as strong as the exogenous variables in the SEE.

[Figure 1]

To provide a more comprehensive understanding of entrepreneurial behaviors, Krueger (2009) combined the TPB and SEE models into a single model (See Fig. 1). This combined 
model is the focus of the present investigation, which includes propensity to act, desirability and feasibility from the SEE, and, social norms and self-efficacy from the TPB model. The new variant included in the KEI is collective efficacy. The rationale behind incorporating collective efficacy is the hypothesis that although one might perceive strong personal abilities, this may not be sufficient alone for entrepreneurship where benefiting from collective abilities is vital for potential entrepreneurs to be successful. This implies that a favorable perception of the abilities of colleagues is an influential factor in explaining entrepreneurial intentionality as well.

Although Krueger (2009) indicates (Fig. 1) that intention impacts action (behavior), there is a significant distinction between an individual's intention toward a behavior i.e., goal intention and what he or she will actually do in the future regarding the intention i.e. action. Setting a goal intention by individuals does little to help researchers measure individual's actual behavior and this has been acknowledged as a limitation in most research involving EI (e.g. Altinay, Madanoglu, Daniele, \& Lashley, 2012; Gurel et al., 2010; Schlaegel \& Koenig, 2014; Shook \& Bratianu, 2010). One might argue that a longitudinal study would be more appropriate with which to examine the intention-behavior nexus, but this per se is not without methodological biases. A relevant example is a survey of individuals' intention to start a new business carried out by Guerrero et al. (2008). They found that, of the student samples being researched, the number of individuals intent on starting their own or co-owned business in the next three years is approximately two times smaller than those individuals intent on starting such a business later. This poses the problem of time lag (a long period of time between intention and actual behavior) in entrepreneurship research, particularly when student samples are chosen.

Further, in contrast to behavioral intention which is a self-reported concept, behavior is an observational concept. Hence, many longitudinal studies use self-reported responses as a 
proxy for actual behavior rather than as an objective measure or observation of behavior (Kautonen, Van Gelderen, \& Fink, 2015). Aside from these potential biases in measuring entrepreneurial behavior and regardless of other factors (e.g., unavailability of financial resources), an EI will not necessarily move to an actual venture launch if there is a failure to develop a resolute implementation intention. The gap between EI and entrepreneurial behavior can be large as individuals may not volitionally pursue their EIs in practice (Elfving, Brännback, \& Carsrud, 2017).

Therefore, based on the above discussion and in accordance with Bagozzi, Dholakia, and Basuroy's (2003) theory of trying, in this paper we substitute the "Entrepreneurial Implementation Intention" (EII) construct for the action construct based on items related to the individuals' intentional decisions. This analysis contributes to the literature by examining a relatively more comprehensive and robust EI model than other studies on the topic where EI is investigated at a general level. Counterintuitively, Krueger (2009) did not explicitly considered distinguishing entrepreneurial goal intentions (EGIs) from EII in his model. He also ignored the importance of this distinction. He argues that it might prove to be of significant practical value to identify whether someone's EI belongs to the EGI or EII. While he posits implicitly that EII is a closer construct to action than EGI, he does not acknowledge this in his model by adding EII.

A further change to the KEI is made here as this model uses two explanatory variables which closely resemble one another, namely personal desirability and perceived desirability. Statistically, although they differ to some extent, this similarity may cause collinearity problems and subsequently imprecise estimates in the analysis. To alleviate this redundancy, we replace "personal desirability" with the more general and important concept of "attitude toward entrepreneurship" adapted from TPB. The influence of this variable on EI, which is discussed in-depth in previous research, is of such importance that it necessitates its inclusion, 
though it is ignored in the KEI. Drawing on the theoretical framework to be discussed in the following section, we extend the limited framework of KEI by including six relationships from the variables of attitude, desirability, social norms, self-efficacy, collective efficacy, and feasibility to EGI and also one path from EGI to EII.

[Figure 2]

Considering the above conceptualization, the new developed integrated model, which to the best of our knowledge has not been examined before in the literature, is illustrated in Fig. 2. The current investigation therefore contributes to the improvement of EI models literature by examining an untested integrated structural model in the field that offers the potential to broaden the scope of TPB and SEE models. The conceptual framework comprises fifteen hypotheses, all of which postulate positive relationships between the constructs. The following section, through a review of the literature, discusses these hypotheses and relationships.

\subsection{Attitude toward entrepreneurship and perceived desirability}

According to Eagly and Chaiken (1993, p. 1), attitude is a "psychological tendency that is expressed by evaluating a particular entity with some degree of favor or disfavor." The global measure of attitude toward entrepreneurship and entrepreneurial behavior reflects individuals' beliefs of how overall desirable or undesirable its outcomes are. In fact, the more positive the attitude toward entrepreneurship, the more favorable the overall perceived desirability of a venture creation (Shook \& Bratianu, 2010). The current paper also considers the relationship between intentionality, desirability, and attitude which, although support for these links has been previously voiced in a variety of studies (e.g., Guerrero et al., 2008), they are not included in the KEI. According to Ajzen (1991), EI hinges on an individual's attitude and desirability toward the behavior. To the extent that one establishes a positive attitude 
toward entrepreneurial behavior and the consequences of its outcomes, the more likely he or she sets EGI to initiate entrepreneurial behaviors such as a venture creation. Based on these propositions, therefore, it is hypothesized that:

$\mathbf{H}_{1}$. There is a positive relationship between attitude toward entrepreneurship and perceived desirability for a venture creation.

$\mathbf{H}_{2}$. There is a positive relationship between attitude toward entrepreneurship and EGI.

$\mathbf{H}_{3}$. There is a positive relationship between perceived desirability for a venture creation and EGI.

\subsection{Perceived social norms}

Social norms here reflect the influence of a society's inherent cultural values and expectations to start entrepreneurial activities (Veciana, Aponte, \& Urbano, 2005). Similar to personal attitude, perceived social norms affect the perception of desirability by those making decisions to establish a self-employment business. As social norms vary across cultures and even within cultures, it is plausible to expect that their effects on the propensity to become an entrepreneur vary according to cultural contexts as well (Shook \& Bratianu, 2010). As Elfving, Brännback, and Carsrud (2009) put forward, in such cultures as the United States, there is more support from society for starting up one's own business than in European countries. Based on a comparative analysis of a student population within the TPB framework, Shook and Bratianu (2010) articulate that in American and Northern European countries where entrepreneurship has been extensively approved, social support may not be a critical factor of EI compared to Eastern European countries. Also, based on Hofstede's national culture dimensions (2003a), it could be argued that social norms have an effect on countries categorized as collectivistic including Asian countries. Applying the discussion to Iran and consistent with the findings of Najafabadi, Zamani, and Mirdamadi's (2016) research 
on Iranian students, we hypothesize that social norms are crucial for determining what business opportunities and prospects are considered desirable to pursue. Therefore:

H. There is a positive relationship between perceived social norms and perceived desirability for a venture creation.

H5. There is a positive relationship between perceived social norms and EGI.

\subsection{Perceived self-efficacy, collective-efficacy and feasibility}

Self-efficacy defined simply as believing in one's own abilities and skills, is the key determinant of perceived feasibility of venture creation as it drives an optimistic self-view in the pursuit of goals (Barbosa, Gerhardt, \& Kickul, 2007). A survey of entrepreneurial intentions of academics at technical faculties of University of Cambridge and University of Ljubljana by Prodan and Drnovsek (2010) reveals that self-efficacy is the most influential factor in explaining academics' EIs, compared to other predictors. Efficacy perceptions also function collectively; that is, one's perceptions as to whether his or her team members are capable of performing the respective actions. Surprisingly, though a review of literature indicates that the importance of self-efficacy in determining entrepreneurial thinking has been widely discussed, there is a scarcity of studies exploring collective-efficacy in this domain and thus, its role remains an elusive one. Of the few exceptions is the theoretical research on corporate entrepreneurship by Shepherd and Krueger (2002) in which it is conceptualized that beliefs about high efficacy, either at individual or group level, leads to high perceived feasibility of corporate entrepreneurial actions. Further, a review of the extant literature on entrepreneurship indicates that no studies to date have empirically tested TPB or SEE models with the collective-efficacy concept included.

$\mathbf{H}_{6}$. There is a positive relationship between perceived self-efficacy and perceived feasibility of a venture creation. 
$\mathbf{H}_{7}$. There is a positive relationship between perceived collective efficacy and perceived feasibility of a venture creation.

$\mathbf{H}_{8}$. There is a positive relationship between perceived self-efficacy and EGI.

H9. There is a positive relationship between perceived collective efficacy and EGI.

$\mathbf{H}_{10}$. There is a positive relationship between perceived feasibility of a venture creation and EGI.

\subsection{Perceived opportunity}

Stevenson and Jarillo (1990) view entrepreneurship as the pursuit of opportunity, conditional on being desirable and feasible. They argue that perception of opportunities varies among people since an individual's desires and abilities are different from others'. According to Shapero and Sokol (1982), understanding the entrepreneurial process requires an understanding of how credible opportunities are. A credible entrepreneurial opportunity hinges on two important antecedents, perceived desirability and perceived feasibility. Thus:

$\mathbf{H}_{11}$. There is a positive relationship between perceived desirability for venture creation and perceived entrepreneurial opportunity.

$\mathbf{H}_{12}$. There is a positive relationship between perceived feasibility of a venture creation and perceived entrepreneurial opportunity.

$\mathbf{H}_{13}$. There is a positive relationship between perceived entrepreneurial opportunity and EGI.

\subsection{Propensity to act and entrepreneurial implementation intention}

According to Shapero and Sokol (1982), when an entrepreneurial opportunity is perceived as credible, the volitional nature of intent means that one should feel a propensity to act upon the opportunity. In fact, it is believed that when propensity to act is high, the impact 
of perception of opportunity on EI becomes stronger, and vice versa. As noted earlier, following the theory of trying (Bagozzi et al., 2003), and due to the potential time-lag and self-reported response biases in longitudinal studies (Kautonen et al., 2015; Souitaris, Zerbinati, \& Al-Laham, 2007), we opted to use entrepreneurial implementation intention (EII) as the proxy for actual behavior. This also represents a more dynamic model involving the pre-birth stage of entrepreneurship compared to those studies that regard entrepreneurship as two static ends of an action of a potential entrepreneur (i.e., to act or not act). Despite significant efforts in the literature to shed light on the theoretical conceptualization of the effect of EII on EGI (Bagozzi et al., 2003; Carsrud, Brannback, Elfving, \& Brandt, 2017; Elfving et al., 2017; Krueger, 2009), researchers to date have yet to examine this influence empirically. Thus, it follows that:

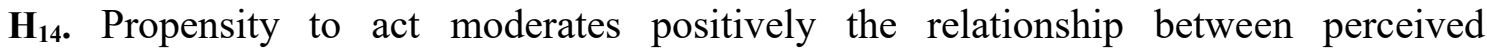
entrepreneurial opportunity and EGI.

$\mathbf{H}_{15}$. There is a positive relationship between EGI and EII.

\section{Research Method}

\subsection{Questionnaire}

In this research, a self-reported Persian questionnaire is adapted by drawing from a variety of established entrepreneurial instruments focusing either on tourism or other domains. In particular, as with the items used for EGI and EII, Elfving et al., (2017) propose that implementation intention is characterized by people who know when, where, and how to plan to pursue a goal. As Krueger (2009) notes, the intention to launch a business is a goal intention, while the intention to launch a business in the near future is an implementation intention. Contrary to EGI, EII is characterized by a short span of time and the subjects' decisiveness to pursue it. Along the same lines, Carsrud et al. (2017) present a continuum of goal pursuits with four stepwise phases. The first phase, predecisional phase, has to do with 
the situation in which people notice what the future could be like, what they want to achieve, and subsequently which goals they wish to set i.e., goal intentions. For example, "I intend to become an entrepreneur."

The second phase, preactional phase, begins when commitment is involved to initiate decisive goal-directed behavior, yet behavior has not commenced i.e., implementation intention. For example, "I intend to start my own company when I have finished my studies." Next, actional phase entails two sub-phases of nascence and action. The former refers to a period of time during which people start primary but concrete initiatives and activities to reach their goal intentions, (for example, "Currently, I am conducting market research or preparing a business plan in order to launch a business"), while the latter refers to the final activities and behaviors conducted in the pursuit of goals (for example, "I launched my own business"). Lastly, in the postactional phase, outcomes are compared to goals.

The items adapted have been modified slightly in order to be consistent with the objectives and the group of samples considered in this research. Two independent bilingual translators applied a translation-back-translation method to the questionnaire, so as to ensure the equivalence of the items in Persian, from the original English version (Howell, 2010; Zeugner-Roth \& Žabkar, 2015). To resolve the discrepancies in the translations, some modifications in grammar and sentence structure were undertaken among the translators. Three academic experts specializing in tourism and quantitative analysis also reviewed the questionnaire to assess each item in terms of clarity and appropriateness of wording (face validity), which led to further minor modifications.

The final survey instrument comprises two parts. The first part includes 46 items to measure the model's ten variables in the context of tourism. These variables are all based on reflective multi-item scales anchored on a seven-point Likert scale ranging from 1 representing "strongly disagree" to 7 representing "strongly agree". The order of some items 
was rotated to avoid sequential response bias (Howell, 2010). Table 1 indicates the final list of 35 items from this part that were remained after statistical data analysis. The second part captures demographic characteristics including age, gender and education. The questionnaire was then pre-tested with a sample of 30 undergraduate and postgraduate tourism students. This led to some minor paraphrasing for those statements that provided low internal consistency or missing values. For example, it was observed that a closed-ended format would provide lower instances of missing data than an open-ended format for the age question.

\subsection{Participants and sampling}

The data for this research were collected from March to May 2015 using self-reported questionnaires administered in person and electronically from a population of tourism students studying at undergraduate (penultimate and final year of study) and postgraduate (Master's) levels. The rationale behind considering these education levels is that they are near to graduation during which it is expected entrepreneurial activities such as starting a business is a more serious choice for students. The students sampled are all citizens of Iran affiliated with four tourism departments from four universities located in Tehran, the country's capital and largest city in terms of population (approximately 9 million people). Though there are no specific "entrepreneurship courses" offered at these departments, both undergraduate and postgraduate students take "business courses" as part of their curriculum. The four universities were selected based on the stratified random sampling technique (Cooper \& Schindler, 2003) out of eight largest public and private universities of the city where there are tourism departments. The subjects were then selected using proportionate random sampling according to the contact information lists.

Following Gurel et al.’s (2010) recommendation, as the screening stage aimed at investigating entrepreneurial intentions before they occur, we asked respondents verbally (for 
in-person administered questionnaires) and also in written form in the questionnaire's introduction section to participate in the survey only if they have not yet launched their own or co-owned full or part-time business in tourism or other fields. After discarding partiallycompleted questionnaires, a total of 390 valid questionnaires were returned (58 and 332 from online and in-person questionnaires, respectively) with a total useful response rate of $66 \%$. The sample group of students ranged in ages from 22 to $41(\mathrm{M}=26.4$ years, $\mathrm{SD}=2.7)$ with slightly more females represented (58.4\%). As for educational attainment, $31 \%$ and $69 \%$ of the sample were undergraduate (penultimate year and final year students) and postgraduate (Master's level) degree students, respectively.

\section{Data analysis}

\subsection{Common method variance}

Common method variance (CMV) in self-report surveys is one of the methodological sources of measurement error with a potential to lessen the reliability and validity of underlying constructs and postulated relations in a model (Fuller, Simmering, Atinc, Atinc, \& Babin, 2016). In the current study, several techniques were used to assess CMV and minimize its potential effects. These techniques were both procedural and statistical. In terms of procedural techniques, the researchers endeavored to design an effective questionnaire in which: (a) ambiguous concepts/items and double-barreled questions were avoided; (b) questions were kept concise; (c) respondents were informed about the anonymity and confidentiality of their responses; (d) respondents were informed that no right or wrong answers exist; (e) some reverse-scored items were designed; and (f) an emphasis was placed on honest answers. These measures would be expected to reduce such method biases as social desirability, consistency motif, and acquiescence (Lindell \& Whitney, 2001; Podsakoff, MacKenzie, Lee, \& Podsakoff, 2003).

As for the statistical controls, Harman's one-factor test indicates when loading the 
models' ten variables into an exploratory factor analysis, the first emerging unrotated factor, with an eigenvalue over one, accounted for $29 \%$ of the overall variance. This is much lower than the 50\% threshold suggested by Podsakoff et al. (2003). Nevertheless, although a widely applied technique (Wu, Raab, Chang, \& Krishen, 2016), due to criticisms against the effectiveness of Harman's one-factor test for detecting CMV (Fuller et al., 2016), the more rigorous technique of marker variable was applied (Lindell \& Whitney, 2001; Zeugner-Roth \& Žabkar, 2015). More precisely, since we did not designate ex ante a theoretically unrelated marker variable in the questionnaire, the post-hoc marker variable approach was considered (Lindell \& Whitney, 2001; Santos-Vijande, López-Sánchez, \& Rudd, 2016; Wamba, Bhattacharya, Trinchera, \& Ngai, 2017). To this end, the smallest correlated item to the model's items was used as a proxy for CMV: "Starting my own business would give me a good quality of life."

The above item was taken from the attitude variable and eliminated due to its low factor loading (see Measurement model section). The mean of the Pearson's correlation coefficients between the marker variable and other items of the ten constructs of the model was 0.086 (mean p-value $=1.4$ ), indicating minimum evidence of CMV. Further, in order to control for CMV, the lowest value of the absolute correlations between the marker variable and other items $\left(r_{\mathrm{s}}=0.012\right)$ was used to adjust all the correlations between the ten constructs and their significances, following Lindell \& Whitney's (2001) suggested equations.

The adjusted correlations were then used to estimate the structural paths of this study's model both with and without the marker variable, employing the partial least squares structural equation modeling (PLS-SEM) technique. The results obtained (not presented) indicate that there are no significant differences between the path coefficient values of the two models when the marker variable is included and excluded. In sum, the arguments above support to the conclusion that CMV is not strong enough to bias this study. 


\subsection{PLS-SEM technique}

The current exploratory paper focuses mainly on testing the newly developed version of the KEI model (Fig. 2), thus its predictive performance, rather than confirmation of its original version (Fig. 1) is taken into account. Therefore, the PLS-SEM technique, due to its appropriate prediction power, is chosen for analyzing the data and proposed hypotheses using SmartPLS software (Carrión, Henseler, Ringle, \& Roldán, 2016; Hair, Hult, Ringle, \& Sarstedt, 2017; Ratzmann, Gudergan, \& Bouncken, 2016). PLS-SEM, as a variance-based technique, has enjoyed increasing popularity in various research disciplines, for instance in tourism (e.g. Wu et al., 2016) and entrepreneurship (e.g. Hernández-Perlines, 2016). Many studies to date have explored an array of factors influencing individuals' intentions to go into business using mainly regression methods (e.g., Gurel et al., 2010; Krueger et al., 2000; Shook \& Bratianu, 2010; Shirokova, Osiyevskyy, \& Bogatyreva, 2015; Soliman, 2011; Wang $\&$ Wong, 2004). In the current study, a more comprehensive view of analyzing the whole set of interrelationships between the constructs using SEM is taken into consideration.

\subsection{Measurement model}

To guarantee scale validity and reliability, as is standard procedure for SEM analysis, the adequacy of the measurement model and structural model are evaluated, respectively. The former is done by gauging the criteria of reliability, convergent validity, and discriminant validity. The model's constructs attained Cronbach's alphas and composite reliability coefficients above the recommended cut-off of 0.7 (see Table 1). The items within each variable therefore exhibit high internal consistency and high reproducibility of the findings (Fornell \& Larcker, 1981).

As to the convergent validity, confirmatory factor analysis and average variance extracted (AVE) criteria were employed. The findings show that most items have a 
standardized factor loading significantly larger than the required minimum of 0.7 with the exception of two items from both constructs of attitude (one of which was applied as the marker variable in the previous section) and self-efficacy as well as one item from the EGI construct. Subsequently, the analysis was rerun with the exclusion of these five items, leading to all the remaining items having a factor loading greater than the 0.7 level. This, coupled with each of the items loading on their original respective variables/dimensions, confirms the convergent validity of the measurement model. Further, after discarding these five items, none of the constructs' AVE were below the 0.5 threshold level. Thus, the amount of variance that the models' variables captured from their items is greater than the amount of variance due to measurement error for these constructs (Fornell \& Larcker, 1981). Table 1 presents the final measurement model criteria.

\section{[Table 1]}

Following Fornell and Larcker (1981), discriminant validity is evaluated by comparing the square roots of the AVE with inter-constructs correlations. As shown in Table 2, in all cases the square root of the AVE of a construct (shown on the diagonal with bold values) exceeds the inter-construct correlation coefficient. Therefore, the measurement model is presumed to have discriminant validity. This implies that, as it was assumed in the survey, the items of each latent variable in the model differ significantly from other latent variables' items (Hair, Sarstedt, Hopkins, \& Kuppelwieser, 2014). However, given that the FornellLarcker (1981) criterion has been subject to debate with critics arguing its reliability to detect a lack of discriminant validity in variance-based SEM studies, the heterotrait-monotrait (HTMT) ratio of correlations (Henseler, Ringle, and Sarstedt, 2015) was also applied here.

The HTMT ratio, one of the new methodological advances in PLS (Carrión et al., 2016) is the average of the heterotrait-heteromethod correlations (i.e., the correlations between 
measurements of constructs measuring different phenomena), relative to the average of the monotrait-heteromethod correlations (i.e., the correlations between measurements of the same construct). The results computed for each pair of the model's ten constructs indicate that the HTMT values of all constructs other than perceived self-efficacy and attitude meet the maximum threshold of 0.85 . To handle this violation, four self-efficacy and two attitude items having low correlations with items in the same construct or high correlations with items in the opposing construct were eliminated, respectively.

The HTMT ratio was thus recomputed for the newly generated constructs along with the former eight constructs, indicating all the values are less than 0.85 (see Table 2). Furthermore, the more liberal HTMT criterion introduced by Henseler et al. (2015) namely HTMT interface was employed to estimate confidence intervals for HTMT using bootstrapping procedure in SmartPLS. The findings obtained (not presented) for all pairs of constructs indicate that value 1 falls outside the confidence internals $(\mathrm{HTMT}<1)$. Thus, the results of the three criteria applied here (Fornell-Larcker, HTMT.85, and HTMT interface) substantiate the discriminant validity of the constructs.

\section{[Table 2]}

\subsection{Structural model}

With respect to the structural model, the SEM procedure based on PLS is applied to analyze Stone-Geisser's $\mathrm{Q}^{2}$, goodness-of-fit, coefficient of determination $\left(\mathrm{R}^{2}\right)$, and path coefficients. To gauge the statistical significance of the path coefficients, following Streukens and Leroi-Werelds's (2016) suggestion for the PLS-SEM context, the bootstrapping process was conducted using 10,000 randomly generated sub-samples to boost the level of accuracy. The values of $\mathrm{Q}^{2}$ in the form of cross-validated redundancy for the model's endogenous variables were found all positive ranging from 0.208 to 0.531 , implying that the model has a capable predictive relevance (Alexander, MacLaren, O'Gorman, \& Taheri, 2012). Also, the 
model's overall GoF is equal to 0.480 obtained from Alolah, Stewart, Panuwatwanich, and Mohamed's (2014) outlines using the equation: GoF $=\sqrt{\overline{\mathrm{AVE}} \times \bar{R}^{2}}$. In this equation, the average AVE of the model's ten latent variables and average $\mathrm{R}^{2}$ of the five endogenous latent variables are taken into account.

Furthermore, the GoF index has been computed for each dependent variable using the respective AVE and $\mathrm{R}^{2}$. Considering the GoF criteria of small: 0.1, medium: 0.25 , and large: 0.36 and the GoF values reported in Table 3, one can argue that the current PLS path modeling has an appropriate overall fit. Finally, according to the $\mathrm{R}^{2}$ coefficients, the modeled constructs explain a moderate amount of $55.7 \%$ variance of EGI, followed by EII (42\%), opportunity (26.5\%), desirability (24.4\%), and feasibility (22.3\%). They all lie at the satisfactory levels of larger than 0.10 suggested by Falk and Miller (1992) but on the other hand, a high portion of the unexplained variances indicate that other important factors beyond the scope of this paper can be set out to help improve explanatory power for these variables.

\subsection{Direct and indirect effects}

Having gained confidence that the measurement and structural models are validated, the next step is to examine the hypotheses. The results of PLS-SEM analysis provide solid support for proposed hypotheses at a significance level of 0.01 , except $H_{4}$ (social norms $\rightarrow$ desirability: $\beta=0.096, t=1.618$ ) and $H_{5}$ (social norms $\rightarrow$ EGI: $\beta=0.074, t=1.523$ ). In particular, attitude has a relatively strong positive impact on desirability with standardized path weight of $0.423(t=18.411)$. At the same time, desirability is the determinant contributing the highest impact on the EGI $(\beta=0.224, t=9.231)$, followed by opportunity $(\beta=$ $0.214, t=8.593)$, feasibility $(\beta=0.187, t=8.947)$, self-efficacy $(\beta=0.178, t=7.569)$, attitude $(\beta=0.103, t=4.627)$, and collective-efficacy $(\beta=0.101, t=4.534)$, respectively. Moreover, self-efficacy $(\beta=0.285, t=10.540)$ and collective efficacy $(\beta=0.253, t=8.628)$ have a relative 
similar impact on feasibility. Feasibility itself positively influences the moderator variable of perceived opportunity $(\beta=0.247, t=8.519)$, while perceived opportunity is more dependent on desirability $(\beta=0.324, t=12.235)$. Finally, the findings show that EGI strongly influences EII, with a path coefficient of $0.648(t=21.312)$. Table 3 represents the detailed results of direct effects and relevant indices.

\section{[Table 3]}

In terms of indirect effects (see Table 4), the two strongest effects originate from attitude on both opportunity $(\beta=0.137, t=2.322)$ and EGI $(\beta=0.092, \mathrm{t}=3.731)$. Other indirect effects are also significant, with the exception of social norms on EGI $(\beta=0.074, t=1.523)$ and opportunity $(\beta=0.031, t=0.681)$. However, following Blanco-Oliver, Veronesi, and Kirkpatrick (2016) when the variance accounted for (VAF) index is considered (using the equation $\left.V A F=\frac{\text { Indirect effect }}{\text { Total } \text { effect }}\right)$, of the constructs affecting both direct and indirect effects, attitude shows the highest ratio of indirect effect to total effect $(\mathrm{VAF}=47.17 \%)$. Comparing the direct impacts and total impacts, of note is that self-efficacy has the second highest total impact on EGI after desirability $(\beta=0.246, t=5.823)$, while it has the fourth highest direct effect on $\mathrm{EGI}(\beta=0.178, t=7.569)$ as mentioned above.

\section{[Table 4]}

\subsection{Moderating effect}

To address the moderation hypothesis (H14) of propensity to act (PTA) between EGI and perceived opportunity, three scenarios were tested and EGI's explanatory powers and effect sizes were compared: (a) the model with all the former variables and paths but without incorporating PTA; (b) an alternative model with PTA as a direct effect on EGI; (C) the model with PTA as a moderator effect (the research model illustrated in Fig. 2). In the first 
scenario, the modeled constructs explained 50.4\% variance of EGI. The results of the second scenario revealed a path coefficient of $0.165(t=5.238)$ between PTA and EGI and an explanatory power $\left(\mathrm{R}^{2}\right)$ of $52.6 \%$ for EGI. To verify the third scenario, taking into account the collinearity problem of the product-indicator approach and also the authors' objective of testing the effect of PTA, the two-stage approach using an interaction term of PTA $\times$ perceived opportunity with standardized indicators was applied (Hair et al. 2017). As shown in Table 5, the model in the third scenario obtained a higher explanatory power of $55.7 \%$ than that of the other two models with the significant path coefficient of $0.153(t=5.787)$ for PTA $\times$ perceived opportunity $\rightarrow$ EGI.

To assess the predictive importance of the scenarios, the $f^{2}$ effect sizes were calculated employing the equation $f^{2}=\frac{R_{\text {mooderator included }}^{2}-R_{\text {mooderator excluded }}^{2}}{1-R_{\text {mooderator included }}^{2}}$, where $R_{\text {moderator included }}^{2}$ and $R^{2}$ moderator excluded are the explanatory powers of a dependent construct (here EGI) when including and excluding the moderator variable (here PTA) from the model, respectively (Felipe, Roldán, \& Leal-Rodríguez, 2016). When comparing the results of the hierarchical difference test (see Table 5), we can conclude that the third scenario with an effect size of 0.069 fits the data best. According to Cohen's (1988) guidelines, this represents a small effect size (i.e., lower than 0.15 ). These outputs altogether confirm $H_{14}$ (the results presented in Table 3 and Table 4 referred to as the third scenario). Therefore, as hypothesized, the impact of perceived opportunity on entrepreneurial intention of tourism students tends to increase when having the propensity to act.

\section{[Table 5]}

\section{Discussion}

This paper tested empirically how intentions that undergraduate and postgraduate tourism students hold toward entrepreneurial activities/decisions are influenced by socio- 
psychological constructs. Other than $H_{4}$ and $H_{5}$ pertaining to the impacts of social norms on desirability and EGI, all other hypotheses could not be rejected. The results highlight that EGI is significantly influenced by desirability, self-efficacy, feasibility, opportunity identification, attitude, and collective efficacy, both directly and indirectly. Notably, from the tourism students' perspective, perception of desirability and self-efficacy matter more for making entrepreneurial intentions than that of feasibility and opportunity identification. A potential explanation for this result might be that the students conceptualize EGI quite distantly from actual entrepreneurial behaviors; hence they play down the critical factors such as feasibility and opportunity.

However, a relatively high correlation found between EGI and EII $\left(H_{15}\right)$ casts doubt on the above explanation in favor of the influence of desirability. Perception of entrepreneurial behaviors as a desirable activity has a stronger effect on how well an individual recognizes business opportunities in the marketplace, compared to how feasible he or she finds entrepreneurial behaviors $\left(\mathrm{H}_{11}\right.$ and $\left.\mathrm{H}_{12}\right)$. The mean scores of the variables also indicate that the students rate desirability higher than self-efficacy and feasibility.

Tourism students truly place more emphasis on their desires for an entrepreneurial career than on feasibility and skills needed to have entrepreneurial career intentions (e.g., to become an entrepreneur and to start and run an own or co-owned firm after graduation). These results conflict with the results of Najafabadi et al. (2016) in which desirability was found to be the fourth strongest factor providing the motivational foundation for forming EIs among Iranian agricultural students, following self-efficacy, psychological traits (risk taking, innovation and creativity, independence, and achievement), and social norms, respectively. Consistent with the findings of $H_{6}$ and $H_{7}$, nurturing students' self- and collective efficacies constitute a contribution to perceived feasibility of EIs. This is in line with prior entrepreneurship research findings (Shepherd \& Krueger, 2002). 
The results show that perceived desirability was significantly influenced by attitude toward entrepreneurship $\left(H_{1}\right)$, but contrary to some literature (Shook \& Bratianu, 2010), it was found that social norms do not affect desirability and EGI. This partially supports the findings of Najafabadi et al.'s (2016) study reporting that social norms have the lowest influence on EIs of Iranian students compared to self-efficacy, attitude, and psychological traits. This might be attributed to the low social legitimacy of entrepreneurship in Iran where the dominant culture and economic barriers encourage people to obtain public sector employment. Another finding to support this argument is that the social norms construct has the lowest mean score compared to other constructs. Based on the two dimensions of this construct, although Iranian tourism students construe normative beliefs as important, their willingness to conform to these norms is low.

According to the path coefficients, perceived desirability and self-efficacy contribute more to the students' EGI, compared to perceived social norms and collective efficacy. Additionally, self-efficacy exerts a more influential effect on perceived feasibility than collective efficacy. Hence, Iranian tourism students may be more individualistic when intending to perform entrepreneurial behavior. Consistent with this, Chen (2015) maintains that self-efficacy has a higher predictive power than collective efficacy in individualistic cultures. Moriano et al. (2012) also note that individualistic societies' willingness to conform to social norms is lower than collectivistic societies.

Contrary to Hofstede's categorization (2003b) that Iranians have a more relative collectivistic culture, this research does not show Iranian tourism students to be particularly collectivistic in the entrepreneurial intentions. Nevertheless, the individualism/collectivism construct was not directly captured in this study and that Hofstede's cultural dimensions do not refer to the student cohort. Parallel to this, Moriano et al.'s (2012) cross-cultural study on students found that social norms significantly affect EIs of students from Netherlands, an 
individualistic country, but not students from the collectivist countries of Iran and Poland. This may partially be because Iranian tourism students are more individualists than Iranian people in general, at least when making an EGI. Thus, there is scope for future research into whether and to what extent the individualism-collectivism dimension of culture could account for variations in EGI, EII and their affecting factors.

Finally, the empirical examination has shed some light on the moderating effect in that having a propensity to act leads to a greater impact of opportunity identification on EGI $\left(H_{14}\right)$. In other words, those tourism students who identify an appropriate business opportunity are more likely to have entrepreneurial intentions, if they have a propensity to act on the intention. In contrast to the SEE model and prior research (e.g. Schlaegel \& Koenig, 2014) in which propensity to act is considered to affect EI directly, our research suggests that the explanatory power of EGI is higher when it is included as a moderating effect upon opportunity. Notably, this interaction term was found to have a stronger impact on students' EGI than on attitude toward entrepreneurship and collective efficacy.

According to Welpe, Spörrle, Grichnik, Michl, and Audretsch (2012), the probability of success and level of profit are two main objective criteria for evaluating a given entrepreneurial opportunity in deciding whether or not to pursue it. More often than not, however, at the same time, these criteria are highly mediated by the subjective evaluation of the opportunity, implying that an ideal positive opportunity will not necessarily result in a propensity to act. As an example, the process of decision making by potential and existing entrepreneurs tends to be influenced by emotions such as fear, anger, and joy on a course of action (Elfving et al., 2017). Future research can include these emotion-related factors in the model introduced in this study for evaluation of entrepreneurial decision making and behavioral processes in the tourism industry. 


\subsection{Theoretical implications}

A major theoretical contribution of the paper is a more comprehensive and robust than Krueger's (2009) integrated model of Entrepreneurial Intention (KEI). Although all variables in the model except collective-efficacy have been previously examined in the literature, this research is the first empirical attempt to consolidate them into a single model. This holistic model enabled us to offer empirical insights into relationships between EGI and its determinants including desirability, self-efficacy, feasibility, opportunity, attitude, and collective-efficacy.

Compared to the KEI, Entrepreneurial Implementation Intention (EII) was substituted for the action construct in the model. This was done to meet the counter-argument against the high relationship between behavioral intentions and actual behavior. The sampled Iranian tourism students, on average, held a moderate intention of implementing their EGIs. In particular, $41 \%$ of tourism students reported a significant EII (the mean scores of 5 or above on a 7-point Likert scale), while a significant EGI is reported by $68 \%$ of the respondents. A high portion of the variance of EII that was not explained by EGI (58\%) in the model indicate that, as the EGI-entrepreneurial action gap has already been mentioned in the literature (Schlaegel \& Koenig, 2014; Elfving et al., 2017), there is also a significant gap between EGI and EII constructs in the area of tourism students.

\subsection{Managerial implications}

Entrepreneurship educators could take advantage of the model introduced in this study as a quantitative instrument to identify the extent to which variables of the model stimulate or deter EIs held by tourism students and more broadly other segments of potential entrepreneurs. Managers and educators can gain a better understanding of which constructs need .This model therefore could be of diagnostic assistance for formulating effective and 
efficient curriculum and educational programs aiming at cultivating entrepreneurial activities. The stronger effect of perceived desirability on EGI than those of perceived self-efficacy and feasibility provides a managerial implication that, while giving credit to the importance of desirability from the subjects' viewpoint, universities should pay more attention to boosting students' self- and collective efficacies by adopting educational programs with an emphasis on entrepreneurial development courses/techniques incorporated in curricula. Techniques in these educational programs may include creative business thinking skills, team working, business start-ups, visitation to prosperous entrepreneurial projects, hands-on entrepreneurial problem-solving exercises, role-playing, meeting successful entrepreneurs, and more broadly, active learning. However, universities in Iran have yet to agree upon a guidance for embedding entrepreneurship training courses in curriculum for tourism management students. As Gurel et al. (2010) put forward, such courses aim to foster students' abilities on how to work for themselves rather than for others, while formal methods of education do not develop students' EIs.

The so-called gap between EGI and EII discussed in the theoretical implication section could be viewed from managerial perspective as well. Educational courses will result in students' "informed EGIs". Once an informed EGI emerges, it will persuade students to make a decision to either quit the EGI or to move one step forward to explore how to transfer it to a lower level of abstractness, namely EII and in turn, entrepreneurial activities. Otherwise, they will volitionally stop at the level of goal intention after graduation (Krueger, 2009; Elfving et al., 2017). In other words, possessing EGI is not enough to lead tourism students to gain EII eventually. This, subsequently, provides a managerial implication that universities should do much more than adding informed EGIs to tourism students. Policies to develop students' commitments to their EGIs and to support their subsequent entrepreneurial activities are crucial. This gives rise to the need to take into account the accelerating factors that serve to 
translate EGIs into EIIs at different stages of the entrepreneurial processes in the tourism industry. For example, according to Castaño, Méndez, and Galindo (2016), in countries with uncomplicated administrative systems and higher financial support for research and development, education, and small to medium-sized enterprises, there is a stronger entrepreneurial culture. However, the opposite is the case in Iran, according to the Global Entrepreneurship Monitor annual report (GEM, 2016).

Based on the national expert ratings of entrepreneurial ecosystem in this report, Iran ranks $66^{\text {th }}, 66^{\text {th }}, 66^{\text {th }}, 65^{\text {th }}, 63^{\text {th }}, 61^{\text {th }}, 56^{\text {th }}$, and $41^{\text {th }}$ out of 66 counties in terms of commercial and legal infrastructure, entry regulation, government entrepreneurship programs, post schoollevel entrepreneurship education, government policies, entrepreneurial finance, R\&D transfer, and physical infrastructure, respectively. Alternatively, based on national population ratings, this report reveals that, interestingly, Iran ranks $5^{\text {th }}, 12^{\text {th }}, 15^{\text {th }}$, and $52^{\text {th }}$ out of 65 countries in terms of perception of EIs, undeterred by fear of failure, self-capabilities, and entrepreneurship career choice, respectively. To conclude, the poor quality entrepreneurial environment might cause students to perceive entrepreneurship as an imperfect career choice and lead to frustration when to demonstrating their EIs, though they might possess high perceptions of self-efficacy and risk-taking propensities. At the strategy and policy level, this means that the tourism industry's entrepreneurial role should be acknowledged as a catalyst to address economic, social, and environmental problems.

\subsection{Limitations}

As with any research, there are several limitations in this research that we suggest be addressed in future studies. First, entrepreneurial implementation intention was used as a proxy for actual behavior construct, based on a single coherent group of university students. Although this opens possible future lines of inquiry for this group, to improve the study's 
external validity, a particularly promising avenue for further research is to account also for nascent (emerging) tourism entrepreneurs, that is, those university tourism students and alumni who, although they have started some initiatives to create their own or co-owned businesses, have not yet launched their business.

As Botsaris and Vamvaka (2016) point out, nascent entrepreneurship is the most proximal indicator of actual entrepreneurial behaviors in the future. A comparative analysis of nascent entrepreneurs and non-entrepreneurs based upon the integrated model presented in this research would provide important insights into differences between these two segments in terms of the mechanism through which the EI's antecedents are associated. That research would also respond to criticisms of research being conducted exclusively among university student populations (Altinay et al., 2012; Gurel et al., 2010; Soliman, 2011). However, the subjects in the current research are students and this limits the ability to generalize the findings to other populations.

The second limitation refers to the operationalization of entrepreneurship concept. According to Hernández-Perlines (2016), entrepreneurship orientation comprises three main dimensions: innovativeness, risk taking, and proactivity. However, the constructs formulated in this research revolve around starting a new own or co-owned business. What is encouraging is that these dimensions were covered implicitly with the items used for perceived self-efficacy, collective efficacy, opportunity, and EGI constructs. We suggest that future research on the topic explicitly incorporate these dimensions as a composite proxy measure to better grasp entrepreneurship orientation of subjects.

Third, analyzing the data on an aggregate level may ignore the possible statistical variation and heterogeneity of EII and EGI in different groups of a set of factors particularly family entrepreneurial background, age, and gender. To ensure sufficient internal validity, closer attention could be paid to these control variables. Finally, a proportion of the data on 
which this study is based was collected through online questionnaires. Even though a number of shortcomings about this method of data collection have been mentioned in the literature, one can cautiously deduce they do not cause a serious concern here since more than five times as many online questionnaires as in-person questionnaires were gathered (58 and 332 online and in-person questionnaires, respectively).

\section{References}

Ajzen, I. (1991). The theory of planned behavior. Organizational Behavior and Human Decision Processes, 50(2), 179-211.

Alexander, M., MacLaren, A., O’Gorman, K., \& Taheri, B. (2012). "He just didn't seem to understand the banter": Bullying or simply establishing social cohesion? Tourism Management, 33(5), 1245-1255.

Alolah, T., Stewart, R. A., Panuwatwanich, K., \& Mohamed, S. (2014). Determining the causal relationships among balanced scorecard perspectives on school safety performance: Case of Saudi Arabia. Accident Analysis \& Prevention, 68, $57-74$.

Altinay, L., Madanoglu, M., Daniele, R., \& Lashley, C. (2012). The influence of family tradition and psychological traits on entrepreneurial intention. International Journal of Hospitality Management, 31(2), 489-499.

Bagozzi, R. P., Dholakia, U. M., \& Basuroy, S. (2003). How effortful decisions get enacted: The motivating role of decision processes, desires, and anticipated emotions. Journal of Behavioral Decision Making, 16(4), 273-295.

Barbosa, S. D., Gerhardt, M. W., \& Kickul, J. R. (2007). The role of cognitive style and risk preference on entrepreneurial self-efficacy and entrepreneurial intentions. Journal of Leadership \& Organizational Studies, 13(4), 86-104.

Blanco-Oliver, A., Veronesi, G., \& Kirkpatrick, I. (2016). Board heterogeneity and organisational performance: The mediating effects of line managers and staff satisfaction. Journal of Business Ethics, 1-15.

Botsaris, C., \& Vamvaka, V. (2016). Attitude toward entrepreneurship: Structure, prediction 
from behavioral beliefs, and relation to entrepreneurial intention. Journal of the Knowledge Economy, 7(2), 433-460.

Carrión, G. C., Henseler, J., Ringle, C. M., \& Roldán, J. L. (2016). Prediction-oriented modeling in business research by means of PLS path modeling: Introduction to a JBR special section. Journal of Business Research, 69(10), 4545-4551.

Carsrud, A., Brännback, M., Elfving, J., \& Brandt, K. (2017). Motivations: The entrepreneurial mind and behavior. In M., Brännback \& A., Carsrud, (Eds.), Revisiting the entrepreneurial mind: Inside the balck box: An expended eidtion (pp. 185-210). New York: Springer.

Castaño, M. S., Méndez, M. T., \& Galindo, M. Á. (2016). The effect of public policies on entrepreneurial activity and economic growth. Journal of Business Research, 69(11), $5280-5285$.

Chen, M.-F. (2015). Self-efficacy or collective efficacy within the cognitive theory of stress model: Which more effectively explains people's self-reported proenvironmental behavior? Journal of Environmental Psychology, 42, 66-75.

Cohen, J. (1988). Statistical power analysis for the behavioral sciences. Mahwah, NJ: Lawrence Erlbaum.

Cooper, D. R., \& Schindler, P. S. (2003). Business research methods (8th ed.). London: McGraw-Hill.

Eagly, A., \& Chaiken, S. (1993). The psychology of attitudes. Orlando: Harcourt Brace Jovanovich.

Echtner, C. M. (1995). Entrepreneurial training in developing countries. Annals of Tourism Research, 22(1), 119-134.

Elfving, J., Brännback, M., \& Carsrud, A. (2009). Toward a contextual model of entrepreneurial intentions. In A. Carsrud \& M. Brännback (Eds.), Understanding the entrepreneurial mind:Opening the black box (pp. 23-33). New York: Springer.

Elfving, J., Brännback, M., and Carsrud, A. (2017). Motivations matter in entrepreneurial behavior: Depends on the context. In M. Brännback \& A. Carsrud (Eds.), Revisiting the entrepreneurial mind: Inside the balck box: An expended eidtion (pp. 211-217). New York: Springer.

Falk, R. F., \& Miller, N. B. (1992). A primer for soft modeling. Akron: University of Akron Press.

Felipe, C. M., Roldán, J. L., \& Leal-Rodríguez, A. L. (2016). An explanatory and predictive model for organizational agility. Journal of Business Research, 69(10), 4624-4631.

Fornell, C., \& Larcker, D. F. (1981). Evaluating structural equation models with unobservable variables and measurement error. Journal of Marketing Research, 18(1), 39-50.

Fuller, C. M., Simmering, M. J., Atinc, G., Atinc, Y., \& Babin, B. J. (2016). Common methods variance detection in business research. Journal of Business Research, 69(8), 3192-3198.

Global Entrepreneurship Monitor. (2016). Global Entrepreneurship Monitor. GEM global reports. Retrieved from http://www.gemconsortium.org/report/ Accessed 29.06.2017.

Guerrero, M., Rialp, J., \& Urbano, D. (2008). The impact of desirability and feasibility on entrepreneurial intentions: A structural equation model. International Entrepreneurship and Management Journal, 4(1), 35-50.

Gurel, E., Altinay, L., \& Daniele, R. (2010). Tourism students' entrepreneurial intentions. Annals of Tourism Research, 37(3), 646-669.

Hair, J. F., Hult, G. T., Ringle, C. M., \& Sarstedt, M. (2017). A primier on partial least squares strcutural equation modeling (PLS-SEM) (2nd ed.). Thousand Oaks, CA: Sage.

Hair, J. F., Sarstedt, M., Hopkins, L., \& Kuppelwieser, V. (2014). Partial least squares 
structural equation modeling (PLS-SEM): An emerging tool in business research. European Business Review, 26(2), 106-121.

Henseler, J., Ringle, C. M., \& Sarstedt, M. (2015). A new criterion for assessing discriminant validity in variance-based structural equation modeling. Journal of the Academy of Marketing Science, 43(1), 115-135.

Hernández-Perlines, F. (2016). Entrepreneurial orientation in hotel industry: Multi-group analysis of quality certification. Journal of Business Research, 69(10), 4714-4724.

Hofstede, G. (2003a). Culture's consequences: Comparing values, behaviors, institutions, and organizations across nations (2nd Ed.). Thousand Oaks, CA: Sage.

Hofstede, G. (2003b). Iran. Retrieved from http://geert-hofstede.com/iran.html/ Accessed 29.06.2017.

Howell, D. C. (2010). Statistical methods for psychology (7th Ed.). Belmont: Cengage Wadsworth.

Kautonen, T., Van Gelderen, M., \& Fink, M. (2015). Robustness of the theory of planned behavior in predicting entrepreneurial intentions and actions. Entrepreneurship Theory and Practice, 39(3), 655-674.

Krueger, N. F. (2009). Entrepreneurial intentions are dead: Long live entrepreneurial intentions. In A. Carsrud \& M. Brännback (Eds.), Understanding the entrepreneurial mind: Opening the black box (pp. 51-72). New York: Springer.

Krueger, N. F., Reilly, M. D., \& Carsrud, A. L. (2000). Competing models of entrepreneurial intentions. Journal of Business Venturing, 15(5-6), 411-432.

Fornell, C., \& Larcker, D. F. (1981). Structural equation models with unobservable variables and measurement error: Algebra and statistics. Journal of Marketing Research, 18(3), 382-388.

Liñán, F., \& Chen, Y.-W. (2009). Development and cross-cultural application of a specific instrument to measure entrepreneurial intentions. Entrepreneurship Theory and Practice, 33(3), 593-617.

Lindell, M. K., \& Whitney, D. J. (2001). Accounting for common method variance in crosssectional research designs. Journal of Applied Psychology, 86(1), 114-121.

Low, M. B., \& MacMillan, I. C. (1988). Entrepreneurship: Past research and future challenges. Journal of Management, 14(2), 139-161.

Moriano, J. A., Gorgievski, M., Laguna, M., Stephan, U., \& Zarafshani, K. (2012). A crosscultural approach to understanding entrepreneurial intention. Journal of Career Development, 39(2), 162-185.

Najafabadi, M., Zamani, M., \& Mirdamadi, M. (2016). Designing a model for entrepreneurial intentions of agricultural students. Journal of Education for Business, 91(6), 338-346.

Podsakoff, P. M., MacKenzie, S. B., Lee, J.-Y., \& Podsakoff, N. P. (2003). Common method biases in behavioral research: A critical review of the literature and recommended remedies. Journal of Applied Psychology, 88(5), 879.

Prodan, I., \& Drnovsek, M. (2010). Conceptualizing academic-entrepreneurial intentions: An empirical test. Technovation, 30(5-6), 332-347.

Ratzmann, M., Gudergan, S. P., \& Bouncken, R. (2016). Capturing heterogeneity and PLSSEM prediction ability: Alliance governance and innovation. Journal of Business Research, 69(10), 4593-4603.

Ryan, T., Mottiar, Z., \& Quinn, B. (2012). The dynamic role of entrepreneurs in destination development. Tourism Planning \& Development, 9(2), 119-131.

Santos-Vijande, M. L., López-Sánchez, J. Á., \& Rudd, J. (2016). Frontline employees' collaboration in industrial service innovation: Routes of co-creation's effects on new service performance. Journal of the Academy of Marketing Science, 44(3), 350-375.

Schlaegel, C., \& Koenig, M. (2014). Determinants of entrepreneurial intent: A meta-analytic 
test and integration of competing models. Entrepreneurship Theory and Practice, 38(2), 291-332.

Shapero, A., \& Sokol, L. (1982). The social dimensions of entrepreneurship. In C. Kent, D. Sexton, \& K. H. Vesper (Eds.), The encyclopedia of entrepreneurship (pp. 72-90). Englewood Cliffs, NJ: Prentice-Hall.

Sharifi-Tehrani, M., Verbič, M., \& Chung, J. Y. (2013). An analysis of adopting dual pricing for museums: The case of the national museum of Iran. Annals of Tourism Research, $43,58-80$.

Shepherd, D. A., \& Krueger, N. F. (2002). An intentions-based model of entrepreneurial teams' social cognition. Entrepreneurship Theory and Practice, 27(2), 167-185.

Shirokova, G., Osiyevskyy, O., \& Bogatyreva, K. (2015). Exploring the intention-behavior link in student entrepreneurship: Moderating effects of individual and environmental characteristics. European Management Journal, 34(4), 386-399.

Shook, C. L., \& Bratianu, C. (2010). Entrepreneurial intent in a transitional economy: An application of the theory of planned behavior to Romanian students. International Entrepreneurship and Management Journal, 6(3), 231-247.

Soliman, D. M. (2011). Entrepreneurial intention among tourism undergraduate students in Egypt. Tourism Analysis, 16(4), 471-481.

Souitaris, V., Zerbinati, S., \& Al-Laham, A. (2007). Do entrepreneurship programmes raise entrepreneurial intention of science and engineering students? The effect of learning, inspiration and resources. Journal of Business Venturing, 22(4), 566-591.

Stevenson, H. H., \& Jarillo, J. C. (1990). A paradigm of entrepreneurship: Entrepreneurial management. Strategic Management Journal, 11(4), 17-27.

Streukens, S., \& Leroi-Werelds, S. (2016). Bootstrapping and PLS-SEM: A step-by-step guide to get more out of your bootstrap results. European Management Journal, 34(6), 618-632.

Veciana, J. M., Aponte, M., \& Urbano, D. (2005). University students' attitudes towards entrepreneurship: A two countries comparison. The International Entrepreneurship and Management Journal, 1(2), 165-182.

Wamba, S. F., Bhattacharya, M., Trinchera, L., \& Ngai, E. W. T. (2017). Role of intrinsic and extrinsic factors in user social media acceptance within workspace: Assessing unobserved heterogeneity. International Journal of Information Management, 37(2), $1-13$.

Wang, C. K., \& Wong, P.-K. (2004). Entrepreneurial interest of university students in Singapore. Technovation, 24(2), 163-172.

Welpe, I. M., Spörrle, M., Grichnik, D., Michl, T., \& Audretsch, D. B. (2012). Emotions and opportunities: The interplay of opportunity evaluation, fear, joy, and anger as antecedent of entrepreneurial exploitation. Entrepreneurship Theory and Practice, 36(1), 69-96.

Wu, K., Raab, C., Chang, W., \& Krishen, A. (2016). Understanding Chinese tourists' food consumption in the United States. Journal of Business Research, 69(10), 4706-4713.

Zeugner-Roth, K. P., \& Žabkar, V. (2015). Bridging the gap between country and destination image: Assessing common facets and their predictive validity. Journal of Business Research, 68(9), 1844-1853. 


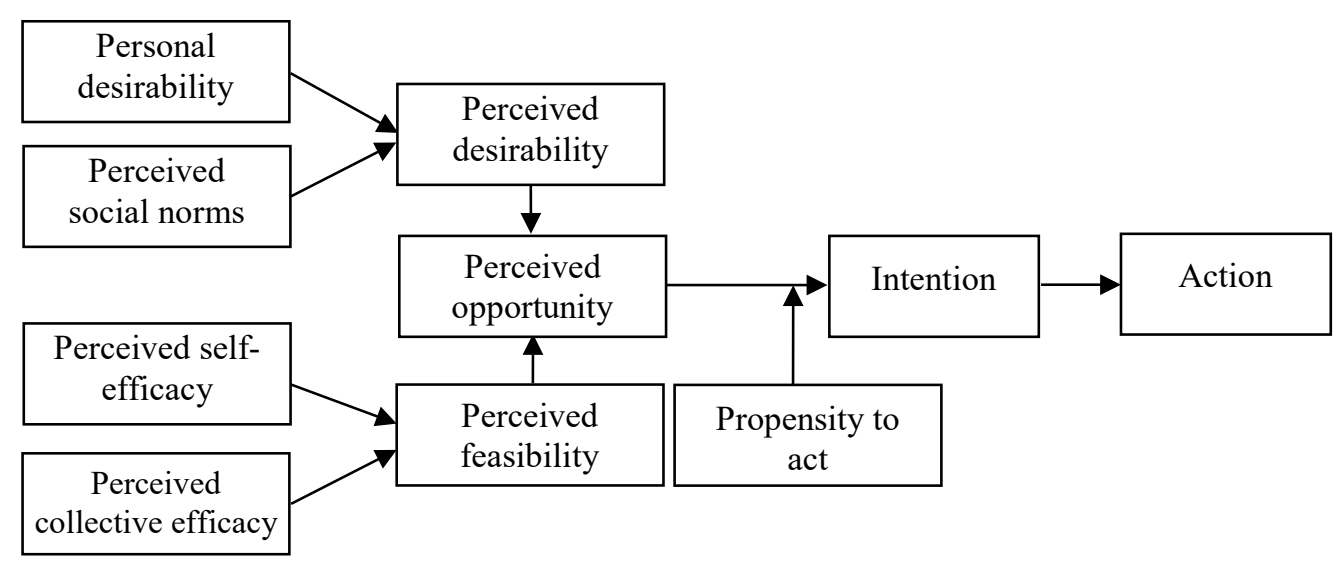

Fig. 1. Model of entrepreneurial intention (Krueger, 2009) 


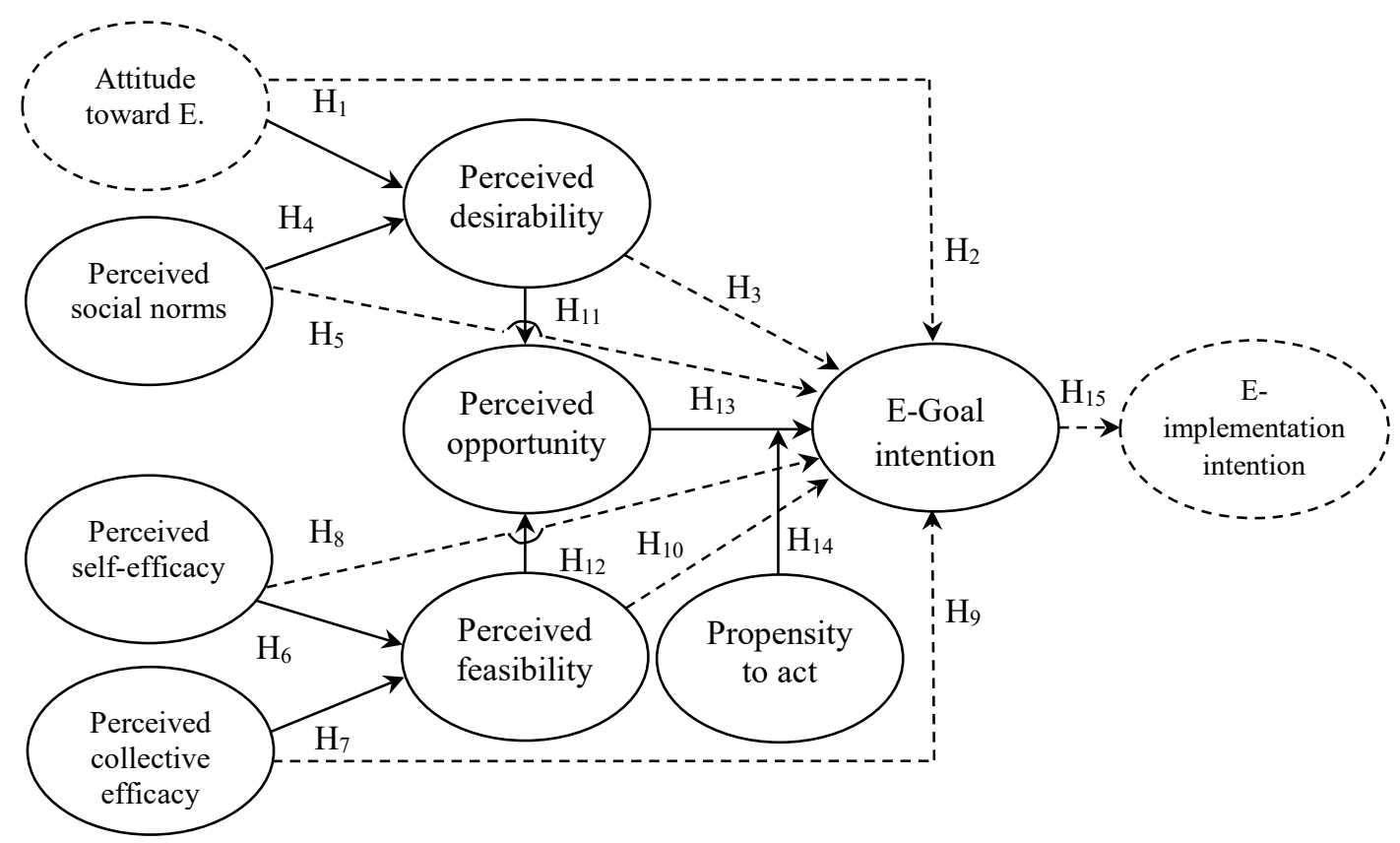

Fig. 2. Research model

Note: Dotted lines indicate added constructs and paths compared to Krueger's (2009) model of entrepreneurial intention 
Table 1. Measurement Model (mean, convergent validity, reliability, discriminant validity)

\begin{tabular}{|c|c|c|c|c|c|c|}
\hline Construct, Item, Source & Mean & $\begin{array}{l}\text { Factor } \\
\text { loading }\end{array}$ & $\begin{array}{c}\mathrm{t}- \\
\text { value }\end{array}$ & CR & $\mathrm{CA}$ & AVE \\
\hline Attitude (Liñán and Chen 2009; Shook \& Bratianu, 2010) & 5.23 & & & .822 & .749 & .598 \\
\hline Being a tourism entrepreneur implies more advantages than disadvantages to me. & & .738 & 13.72 & & & \\
\hline A career as a tourism entrepreneur is attractive rather than unattractive for me. & & .829 & 18.97 & & & \\
\hline The autonomy of starting my own tourism business is enjoyable rather than unenjoyable. & & .727 & 12.78 & & & \\
\hline The financial reward of starting my own tourism business is enjoyable rather than unenjoyable. & & .767 & 14.93 & & & \\
\hline Social norms (Shook \& Bratianu, 2010) & 4.28 & & & .811 & .747 & .592 \\
\hline If I were to start my own tourism business, my parents would be supportive. & & .739 & 13.25 & & & \\
\hline If I were to start my own tourism business, my close friends would be supportive. & & .866 & 18.23 & & & \\
\hline If I were to start my own tourism business, my significant other would be supportive. & & .747 & 15.40 & & & \\
\hline If I were to start my own tourism business, my parents' opinions are important to me. & & .729 & 12.45 & & & \\
\hline If I were to start my own tourism business, my close friends' opinions are important to me. & & .717 & 11.61 & & & \\
\hline If I were to start my own tourism business, my significant other's opinion is important to me. & & .820 & 18.12 & & & \\
\hline Self-efficacy (Shook \& Bratianu, 2010) & 5.16 & & & .816 & .788 & 630 \\
\hline I can tolerate unexpected changes in business conditions. & & .740 & 15.83 & & & \\
\hline I can react quickly to take advantage of business opportunities. & & .847 & 20.29 & & & \\
\hline I can originate new business ideas and products. & & .770 & 14.24 & & & \\
\hline I can create products that fulfill customers' unmet needs. & & .832 & 20.23 & & & \\
\hline I do not have the skills and capabilities required to succeed as a tourism entrepreneur (reversed & & .816 & 18.98 & & & \\
\hline I can develop a well-conceived plan and presentation to potential investors. & & .758 & 15.07 & & & \\
\hline Collective efficacy (Chen, 2015) & 4.85 & & & .815 & .768 & .632 \\
\hline $\begin{array}{l}\text { I am sure that by collective oriented activities as a unit, we cannot do much to launch a tourism } \\
\text { business (reverse coded). }\end{array}$ & & .773 & 14.70 & & & \\
\hline $\begin{array}{l}\text { Considering I have gathered a team to launch a tourism business, I believe our team members' } \\
\text { abilities and skills needed to succeed. }\end{array}$ & & .745 & 11.59 & & & \\
\hline $\begin{array}{l}\text { Considering I have gathered a team to launch a tourism business, I am confident that the team } \\
\text { as a unit can come up with creative ideas to solve start-up tourism business problems } \\
\text { effectively. }\end{array}$ & & .867 & 29.28 & & & \\
\hline Desirability (Shook \& Bratianu, 2010) & 5.47 & & & .859 & .773 & .770 \\
\hline I consider starting my own business very desirable. & & .871 & 31.26 & & & \\
\hline I consider an entrepreneurial career to be very desirable. & & .885 & 36.71 & & & \\
\hline Feasibility (Shook \& Bratianu, 2010) & 4.86 & & & .902 & .855 & .580 \\
\hline It would be practical for me to start my own or co-owned tourism business. & & .778 & 14.10 & & & \\
\hline It would be feasible for me to start my own or co-owned tourism business. & & .746 & 13.45 & & & \\
\hline Opportunity (GEM, 2016) & & & & .814 & .758 & 0.755 \\
\hline I've seen good opportunities for starting up a tourism business. & & .891 & 41.85 & & & \\
\hline I will identify a good opportunity in tourism start-up in the near future. & & .847 & 19.40 & & & \\
\hline Propensity to act (Shapero \& Sokol, 1982) & 5.27 & & & .822 & .761 & 0.730 \\
\hline $\begin{array}{l}\text { If I see a good opportunity in starting up a tourism business, I will have a good deal of } \\
\text { propensity to act upon that opportunity. }\end{array}$ & & .853 & 20.01 & & & \\
\hline If I see a good opportunity in starting up a tourism business, I will decide to take action. & & .867 & 30.51 & & & \\
\hline If I see a good opportunity in starting up a tourism business, I will be eager to act upon it. & & .842 & 19.10 & & & \\
\hline E-goal-intention (Krueger, 2009; Carsrud et al., 2017; Botsaris and Vamvaka, 2016; & 5.76 & & & .727 & .788 & .656 \\
\hline Liñán \& Chen, 2009) & & .719 & 11.43 & & & \\
\hline One of my professional goals is to become a tourism entrepreneur. & & .825 & 15.36 & & & \\
\hline I will make every effort to start and run my own or co-owned firm. & & .834 & 19.51 & & & \\
\hline $\begin{array}{l}\text { I want to start my own or co-owned tourism business sometime in the future. } \\
\text { My intention is to be employed by others rather than being self-employed (reversed coded). }\end{array}$ & & .863 & 29.41 & & & \\
\hline E-implementation-intention (Bagozzi et al. 2003; Krueger, 2009) & 4.31 & & & .822 & .837 & .745 \\
\hline I am determined to create my own or co-owned tourism business in the near future. & & .865 & 29.71 & & & \\
\hline I have very seriously thought of starting a tourism firm. & & .816 & 18.34 & & & \\
\hline The probability of starting my own or co-owned tourism business is high in the next 3 years. & & .910 & 41.56 & & & \\
\hline
\end{tabular}

Notes: $\mathrm{CR}=$ Composite reliability, $\mathrm{CA}=$ Cronbach's alpha, $\mathrm{AVE}=$ average variance extracted. 
Table 2. Correlations and discriminant validity by Fornell-Larcker criterion and Heterotrait-monotrait (HTMT) ratios

\begin{tabular}{lcccccccccc}
\hline Construct & 1 & 2 & 3 & 4 & 5 & 6 & 7 & 8 & 9 & 10 \\
\hline 1. Attitude & $\mathbf{. 7 7 3}$ & .284 & .215 & .120 & .519 & .419 & .304 & .395 & .416 & .211 \\
2. Social norms & .276 & $\mathbf{. 7 7 0}$ & .189 & .129 & .251 & .205 & .112 & .226 & .319 & .205 \\
3. Self-Efficacy & .227 & .189 & .793 & .191 & .348 & .385 & .484 & .188 & .503 & .399 \\
4. Collective Efficacy & .117 & .124 & .183 & .795 & .341 & .341 & .532 & .221 & .395 & .354 \\
5. Desirability & .514 & .240 & .341 & .330 &. $\mathbf{8 7 7}$ & .504 & .411 & .344 & .686 & .521 \\
6. Opportunity & .302 & .114 & .357 & .295 & .492 & $\mathbf{. 8 6 9}$ & .489 & .489 & .671 & .369 \\
7. Feasibility & .275 & .032 & .428 & .406 & .370 & .428 & .761 & .410 & .475 & .369 \\
8. Propensity to act & .505 & .176 & .275 & .173 & .531 & .437 & .320 & $\mathbf{. 8 5 4}$ & .506 & .458 \\
9. Goal-Intention & .391 & .315 & .491 & .389 & .678 & .655 & .455 & .414 &. $\mathbf{8 1 0}$ & .655 \\
10. Implementation-intention & .203 & .181 & .386 & .338 & .453 & .366 & .361 & .434 & .648 & .863
\end{tabular}

Notes: Diagonal elements (bold) are the square roots of AVEs.

Below the diagonal elements are the correlations between the constructs. Above the diagonal elements are the HTMT ratios. 
Table 3. Path coefficient and hypothesis testing (Direct effect)

\begin{tabular}{|c|c|c|c|c|c|c|c|c|c|}
\hline Dependent variable & $\begin{array}{l}\text { Independent } \\
\text { variable }\end{array}$ & Hypothesis & $\begin{array}{c}\text { Path } \\
\text { coefficient }\end{array}$ & t-value & $\begin{array}{l}\text { Hypothesis } \\
\text { result }\end{array}$ & $\mathrm{R}^{2}$ & Adj. $R^{2}$ & $\mathrm{Q}^{2}$ & GoF \\
\hline \multirow[t]{2}{*}{ Desirability } & Attitude & H1 & $.423^{* * *}$ & 18.411 & Supported & .244 & .236 & .235 & .430 \\
\hline & Social norms & $\mathrm{H} 4$ & $.096 \mathrm{~ns}$ & 1.618 & Rejected & & & & \\
\hline \multirow[t]{8}{*}{ Goal intention } & Attitude & $\mathrm{H} 2$ & $.103^{* * *}$ & 4.627 & Supported & .557 & .548 & .531 & .604 \\
\hline & Desirability & $\mathrm{H} 3$ & $.224^{* * *}$ & 9.231 & Supported & & & & \\
\hline & Social norms & H5 & $.074 \mathrm{~ns}$ & 1.523 & Rejected & & & & \\
\hline & Self-efficacy & $\mathrm{H} 8$ & $.178^{* * *}$ & 7.569 & Supported & & & & \\
\hline & Collective efficacy & $\mathrm{H} 9$ & $.101^{* * *}$ & 4.534 & Supported & & & & \\
\hline & Feasibility & $\mathrm{H} 10$ & $.187^{* * *}$ & 8.947 & Supported & & & & \\
\hline & Opportunity & H13 & $.214^{* * *}$ & 8.593 & Supported & & & & \\
\hline & $\begin{array}{l}\text { Propensity to act } \times \\
\text { opportunity }\end{array}$ & H14 & $.153^{* * *}$ & 5.787 & Supported & & & & \\
\hline \multirow[t]{2}{*}{ Feasibility } & Self-efficacy & H6 & $.285^{* * *}$ & 10.540 & Supported & .223 & .219 & .208 & .360 \\
\hline & Collective efficacy & $\mathrm{H} 7$ & $.253^{* * *}$ & 8.628 & Supported & & & & \\
\hline \multirow[t]{2}{*}{ Opportunity } & Desirability & H11 & $.324^{* * *}$ & 12.235 & Supported & .265 & .261 & .240 & .447 \\
\hline & Feasibility & $\mathrm{H} 12$ & $.247^{* * *}$ & 8.519 & Supported & & & & \\
\hline Implementation intention & Goal intention & $\mathrm{H} 15$ & $.648^{* * *}$ & 21.312 & Supported & .420 & .418 & .416 & .560 \\
\hline
\end{tabular}


Table 4. Direct, indirect and total effects on dependent variables

\begin{tabular}{|c|c|c|c|c|c|c|c|c|}
\hline \multirow[t]{2}{*}{ Dependent variable } & \multirow{2}{*}{$\begin{array}{l}\text { Independent } \\
\text { variable }\end{array}$} & \multicolumn{2}{|c|}{ Direct effect } & \multicolumn{2}{|c|}{ Indirect effect } & \multicolumn{2}{|c|}{ Total effect } & \multirow{2}{*}{$\begin{array}{l}\text { VAF } \\
(\%)\end{array}$} \\
\hline & & $\mathrm{b}^{\mathrm{a}}$ & $\mathrm{t}^{\mathrm{b}}$ & $\mathrm{b}$ & $\mathrm{T}$ & $\mathrm{b}$ & $\mathrm{t}$ & \\
\hline \multirow[t]{7}{*}{ Goal intention } & Attitude & $.103^{* * *}$ & 4.627 & $.092^{* * *}$ & 3.731 & $.195^{* * *}$ & 3.714 & 47.17 \\
\hline & Desirability & $.224^{* * *}$ & 9.231 & $.071^{* * *}$ & 3.180 & $.295^{* * *}$ & 5.823 & 24.06 \\
\hline & Social norms & $.074 \mathrm{~ns}$ & 1.523 & $.029 \mathrm{~ns}$ & .644 & $.103 \mathrm{~ns}$ & 1.233 & 28.15 \\
\hline & Self-efficacy & $.178^{* * *}$ & 7.569 & $.068^{* * *}$ & 2.738 & $.246^{* * *}$ & 6.661 & 27.64 \\
\hline & Collective efficacy & $.101^{* * *}$ & 4.534 & $.060^{* *}$ & 2.545 & $.161^{* * *}$ & 5.679 & 37.26 \\
\hline & Feasibility & $.187^{* * *}$ & 8.947 & $.053^{* *}$ & 2.353 & $.240^{* * *}$ & 7.426 & 22.08 \\
\hline & Opportunity & $.214^{* * *}$ & 8.593 & - & - & $.214^{* * *}$ & 8.593 & - \\
\hline \multirow[t]{4}{*}{ Opportunity } & Attitude & & & $.137^{* *}$ & 2.322 & $.137^{* *}$ & 2.322 & 100 \\
\hline & Social norms & & & $.031 \mathrm{~ns}$ & .681 & $.031 \mathrm{~ns}$ & .681 & 100 \\
\hline & Self-efficacy & & & $.070^{* * *}$ & 2.792 & $.070^{* * *}$ & 2.792 & 100 \\
\hline & Collective-efficacy & & & $.062^{* *}$ & 2.574 & $.062^{* *}$ & 2.574 & 100 \\
\hline
\end{tabular}

Notes: ${ }^{\mathrm{a}}$ : path coefficient, ${ }^{\mathrm{b}}$ : t-value, ns: not significant, ${ }^{* *} p<.05, * * * p<.01$ (two-sided test). 
Table 5. Interaction effect test

\begin{tabular}{lll}
\hline Scenario & $\mathrm{R}^{2}$ & Effect size \\
\hline Model without PTA & .504 & \\
Model with PTA as a direct effect & .526 & .119 \\
Model with PTA as a moderator & .557 & .069 \\
\hline
\end{tabular}

